\author{
K.H.Stricker \\ H. U. Rothen \\ J. Fuhrer
}

\section{Atrial tachyarrhythmia after cardiac surgery}

Received: 8 June 1997

Accepted: 15 October 1997

K.H. Stricker · H.U. Rothen

Institute for Anaesthesiology and Intensive Care,

University Hospital of Bern, Switzerland

J. Fuhrer (

Cardiology, University Hospital, Inselspital,

3010 Bern, Switzerland

Fax: + 41 (31) 6324299

email: juerg.fuhrer@insel.unibe.ch

\section{Introduction}

Today an increasing number of patients require cardiac surgery. They are often elderly and have severe cardiac disease, thus constituting an important risk for perioperative complications. Atrial tachyarrhythmia, such as atrial fibrillation, atrial flutter, or atrial tachycardia, frequently complicates cardiac surgery and is now recognized as a major cause of morbidity. Hypotension, hemodynamic instability, congestive heart failure, and thromboembolic complications due to postoperative atrial tachyarrhythmias may lengthen the period of hospitalization and increase costs.

Here we review risk factors and pathophysiological mechanisms of postoperative atrial tachyarrhythmia. Prophylactic and therapeutic measures are discussed.

\section{Incidence and time occurrence of atrial tachyarrhythmias}

The reported incidence of atrial tachyarrhythmias following cardiac surgery varies from 10 to $40 \%$ in the postoperative period [1-19]. This wide range is at least in part due to differences in the protocols of the studies cited. Patient populations, type of cardiac surgery, definition, duration, and hemodynamic effect of atrial tachyarrhyth- mia, withdrawal of antiarrhythmic drugs used preoperatively, and duration and type of postoperative rhythm monitoring frequently vary, making it difficult to indicate precisely the true incidence of this complication. Despite increasing expertise in managing patients undergoing cardiac surgery, the incidence of these arrhythmias seems not to have declined in the past $10-15$ years $[17,20]$. Atrial tachyarrhythmias can develop immediately or several days after surgery. They are most often observed during the second to fourth postoperative day $[1-3,6,10-12,15$, $18,21-28]$. Sustained atrial fibrillation and flutter are often preceded by atrial ectopic activity, atrial tachycardia, or nonsustained atrial fibrillation $[13,25]$.

\section{Etiology and risk factors of atrial tachyarrhythmias}

In patients who have not had cardiac surgery, the mechanisms underlying atrial fibrillation have been studied extensively. Several models have been developed. Based on mathematical modelling the "multiple wavelet hypothesis" has been proposed [29], which suggests that excitation of the atrium during fibrillation is the consequence of multiple, self-sustaining re-entrant wavelets. The electrophysiological basis for this model was described as the "leading circle reentry" in a rabbit model [30], in which electrical activation becomes fractionated as it divides about islets of refractory tissue (circular movement around an area of functional block). Further support for the re-entrant mechanism resulted from the demonstration of local entrainment of the arrhythmia during rapid pacing [31].

In some patients without structural heart disease the surface electrocardiographic pattern of atrial fibrillation is due to a focal, rapidly firing source of activity. These sources have been identified and successfully eliminated by radiofrequency ablation [32].

Much less is known of the pathophysiology of postoperative atrial fibrillation. Whether the responsible 
factors lead either to abnormally high inducibility or to abnormally high stability of established atrial fibrillation is unclear. A number of cardiac-associated perioperative problems are thought to be responsible: postoperatively raised levels of catecholamines [33] (in some cases intensified by withdrawal of beta blockers) or pericarditis [34] may be involved. With increasing age, atrial dilatation $[35,36]$, enlarged left ventricular mass [35], and calcification of the mitral annulus [36, 37] are more common. It is possible that these are responsible for atrial conduction delay, and they probably represent in many patients a critical prerequisite for atrial re-entry and arrhythmia. Thus, the signal-averaged electrocardiogram is a potent predictor of atrial fibrillation after cardiac surgery [11].

Whereas hypokalemia is known to be related to ventricular arrhythmia, a correlation to supraventricular arrhythmia in patients after cardiac surgery is controversial $[38,39]$. Thus, myocardial potassium concentration in the right atrium was similar in patients experiencing atrial fibrillation compared to patients with sinus rhythm [28].

It is clearly desirable to identify risk factors for atrial tachyarrhythmias. Several important studies have found increasing age $[6,16,17,20,25,28,40,41]$, heart valve surgery $[16,42]$, a history of atrial fibrillation $[16$, $41,42]$, and prolonged signal-averaged $p$-wave duration $[11,43]$ to be predictive of postoperative atrial tachyarrhythmia. Conflicting results have been published for: sex $[6,16,17,20,40,43,44]$, left ventricular end-diastolic pressure $[20,40,41]$, aortic cross-clamp time $[16,20$, $25,28,40,43-45]$, arterial hypertension [17, 20, 43], ejection fraction $[20,40,43,45]$, and chronic obstructive pulmonary disease $[16,20]$. Postoperative withdrawal of beta blockers has been identified as a possible risk factor for atrial tachyarrhythmia, but no controlled study has addressed this question. The number of bypass grafts $[25,40,43,44]$ and a prior history of myocardial infarction $[16,40,43,44]$ are not risk factors.

\section{Consequences of postoperative atrial tachyarrhythmia}

Atrial tachyarrhythmia may be of short duration and is often well tolerated $[3,24,45]$. By contrast, it can lead to important hemodynamic deterioration with a significant decline in cardiac output leading to congestive heart failure [16]. This complication is frequently observed in patients with pre-existing cardiac ischemia, poor left ventricular function, rapid ventricular rate, or reduced ventricular compliance. The poorly compliant ventricle needs atrial contraction in order to gain sufficient preload. A significant increase in cardiac index from 2.7 to $3.4 \mathrm{l} / \mathrm{min}$ per $\mathrm{m}^{2}$ as well as a decrease in pulmonary arterial diastolic pressure have been observed in patients who converted from postoperative atrial fibrillation to sinus rhythm [46]. A rapid conversion to sinus rhythm is therefore imperative in patients with hemodynamic instability.

Atrial tachyarrhythmia can lead to systemic thromboembolism and cause transient, or severe and persistent, neurologic deficit [6, 20, 47-49]. After coronary artery bypass in 453 patients, atrial fibrillation alone increased the probability of stroke or transient ischemic attack from 0.78 to $3.9 \%$ during the postoperative period [49]. In 108 patients with carotid bruits, postoperative atrial fibrillation was an important risk factor for stroke or transient ischemic attack [47]. Patients with a previous history of cerebrovascular events were at highest risk for this severe complication.

Patients with atrial tachyarrhythmia stay significantly longer in the intensive care unit (ICU), are more often readmitted to the ICU $[16,19,20,50]$. and have a longer total duration of hospitalization $[3,12,16,51]$, resulting in additional costs estimated variously at U.S. $\$ 1600$ etc. [16], U.S. $\$ 4500$ [7], U.S. $\$ 8000$ [19], or U.S. $\$ 10000$ [17]. Whereas other factors often associated with postoperative atrial tachyarrhythmia (such as age and postoperative complications) contribute to prolonged hospitalization, atrial fibrillation is independently associated with an increased length of stay of 4.9 days [17]. Postoperative atrial fibrillation is therefore an important drain on hospital resources, contributing significantly to the escalating health costs associated with coronary artery bypass grafting.

\section{Prevention of postoperative atrial tachyarrhythmias}

It has been suggested that routine pharmacological prophylaxis of postoperative atrial tachyarrhythmia may lead to the administration of unnecessary medication to a majority of patients, with a financial burden and risk of pharmacologic side effects $[3,50]$. However, considering the medical and financial consequences of postoperative atrial tachyarrhythmias, it is obvious that an effective, nontoxic prophylactic drug regimen, at least for patients at risk, would be highly desirable. An overview of trials evaluating the efficiency of drugs in preventing postoperative atrial tachyarrhythmias is presented in Table 1 . Summarized are only prospective randomized trials including at least 50 patients.

Propafenone has been compared in a double-blinded study with atenolol in 207 patients [14]: the incidence of atrial tachyarrhythmias was the same in both groups, although preoperative beta blockers were stopped in the propafenone group.

Beta blockers are the most widely studied agents applied for prophylactic purposes: propranolol $[1,3,15$, 52], acebutolol [22], atenolol [5], metoprolol [2], and nadolol [4] have all been compared to placebo. In all trials, 
Table 1 Drug efficiency in prophylaxis of postoperative atrial tachyarrhythmia (randomized, prospective studies published from 1976 to 1997 including at least 50 patients)

\begin{tabular}{|c|c|c|c|c|c|c|}
\hline Authors & Type of study & Number of patients & Type of operation & Proceeding $A$ and effic & ciency $^{\mathrm{a}}$ & Proceeding B \\
\hline Johnson et al. [23] & Open & 120 & CABG & Digitalis & $>$ & No prophylaxis \\
\hline Tyras et al. [48] & Open & 140 & $\mathrm{CABG}$ & Digitalis & $<$ & No prophylaxis \\
\hline Csicsko et al. [57] & Open & 407 & CABG & Digitalis & $>$ & No prophylaxis \\
\hline Hammon et al. [52] & Double-blinded & 50 & $\mathrm{CABG}$ & Propranolol & $>$ & Placebo \\
\hline Matangi et al. [1] & Open & 164 & CABG & Propranolol & $>$ & No prophylaxis \\
\hline Williams et al. [27] & Double-blinded & 141 & CABG & Verapamil & $=$ & Placebo \\
\hline Smith et al. [24] & Open & 100 & $\mathrm{CABG}$ & Verapamil & $=$ & No prophylaxis \\
\hline Davison et al. [55] & Double-blinded & 200 & CABG & Verapamil & $=$ & Placebo \\
\hline Daudon et al. [22] & Open & 100 & $\mathrm{CABG}$ & Acebutolol & $>$ & No prophylaxis \\
\hline Janssen et al. [2] & Open & 1251 & $\mathrm{CABG}$ & $\begin{array}{l}\text { Sotalol } \\
\text { Metoprolol } \\
\text { Sotalol }\end{array}$ & $\begin{array}{l}> \\
> \\
>\end{array}$ & $\begin{array}{l}\text { No prophylaxis } \\
\text { No prophylaxis } \\
\text { Metoprolol }\end{array}$ \\
\hline Rubin et al. [3] & Open & 123 & $\mathrm{CABG}$ & $\begin{array}{l}\text { Propranolol } \\
\text { Digitalis }\end{array}$ & $\begin{array}{l}> \\
=\end{array}$ & $\begin{array}{l}\text { No prophylaxis } \\
\text { No prophylaxis }\end{array}$ \\
\hline Khuri et al. [4] & Double-blinded & 148 & CABG & Nadolol & $>$ & Placebo \\
\hline Lamb et al. [5] & Open & 60 & $\mathrm{CABG}$ & Atenolol & $>$ & No prophylaxis \\
\hline Suttorp et al. [44] & Double-blinded & 300 & $\mathrm{CABG}$ & Sotalol & $>$ & Placebo \\
\hline Hohnloser et al. [54] & Open & 77 & $\mathrm{CABG}$ & Amiodarone & $>$ & Placebo \\
\hline Fanning et al. [8] & Double-blinded & 99 & CABG & Magnesium & $=$ & Placebo \\
\hline England et al. [9] & Double-blinded & 100 & $\begin{array}{l}\text { CABG, } \\
\text { AVS, MVS }\end{array}$ & Magnesium & $=$ & Placebo \\
\hline Parikka et al. [56] & Open & 140 & CABG & Magnesium & $=$ & Placebo \\
\hline Nyström et al. [26] & Open & 101 & $\mathrm{CABG}$ & Sotalol & $>$ & $\begin{array}{l}\text { Half dose of } \\
\text { preoperative } \\
\beta \text {-blocker }\end{array}$ \\
\hline Merrick et al. [14] & Double-blinded & 207 & $\begin{array}{l}\text { CABG, } \\
\text { AVS, MVS }\end{array}$ & Propafenone & $=$ & Atenolol \\
\hline Babin-Ebell et al. [15] & Open & 103 & $\mathrm{CABG}$ & $\begin{array}{l}\text { Propranolol } \\
\text { Diltiazem }\end{array}$ & $\begin{array}{l}> \\
=\end{array}$ & $\begin{array}{l}\text { No prophylaxis } \\
\text { No prophylaxis }\end{array}$ \\
\hline Kowey et al. [19] & Double-blinded & 157 & $\mathrm{CABG}$ & Digitalis + acebutolol & $=$ & $\begin{array}{l}\text { Digitalis + } \\
\text { placebo }\end{array}$ \\
\hline
\end{tabular}

a $>$ : Proceeding A significantly more efficient in preventing postoperative atrial tachyarrhythmia compared to proceeding $\mathrm{B} ;=:$ no significant difference; <: proceeding A significantly less efficient in preventing postoperative atrial tachyarrhythmia compared to drug $\mathrm{B}$ ( $C A B G$ coronary artery bypass grafting, $A V S$ aortic valve surgery, $M V S$ mitral valve surgery) postoperative atrial tachyarrhythmia was significantly reduced, although preoperative therapy with beta blockers was sometimes suspended in the control groups. This withdrawal may be a risk factor for postoperative atrial tachyarrhythmia and may lead to a false high incidence in the placebo groups.

A meta-analysis of 14 studies incorporating a total of 2585 patients treated either with prophylactic beta blockers $(n=675)$, digitalis $(n=375)$, a combination of both $(n=139)$, or placebo $(n=1414)$ revealed the combination of beta blockers and digitalis to be significantly more effective than beta blockers alone, which in turn was significantly superior to placebo [53]. Digitalis alone had no significant effect and showed only a trend toward benefit. However, meta-analyses can never be used as final statements, as the nonuniformity of the different studies may make comparison difficult. Furthermore, in a recent study, no significant additional effect of acebutolol could be demonstrated when given in conjunction with digitalis [19].

Amiodarone [54] and sotalol [2, 26, 44] have been compared to placebo in several open and double-blinded trials. In all studies, a significant reduction in postoperative atrial tachyarrhythmia was observed. Again, in the placebo groups preoperative beta blockers or other cardiac medication were reduced or completely stopped, which may have led to a false high incidence of postoperative atrial tachyarrhythmias in these groups. In a study comparing sotalol with metoprolol, sotalol was significantly more effective [2]. 
Table 2 Drug efficiency in conversion of postoperative atrial tachyarrhythmia to sinus rhythm (only randomized and prospective studies, 1982-1997)

\begin{tabular}{|c|c|c|c|c|c|c|}
\hline Authors & Type of study & Number of patients & Type of operation & $\begin{array}{l}\text { Proceeding A } \\
\text { and efficiency } \\
\text { of conversion }\end{array}$ & & Proceeding $\mathrm{B}$ \\
\hline Plumb et al. [68] & Double-blinded & 28 & $\mathrm{CABG}, \mathrm{AVS}, \mathrm{CC}$ & Verapamil & $=$ & Placebo \\
\hline Hwang et al. [58] & Double-blinded & 14 & $\mathrm{CABG}, \mathrm{ASD}$ & Verapamil & $=$ & Placebo \\
\hline Campbell et al. [66] & Open & 40 & Not specified & Sotalol & $=$ & $\begin{array}{l}\text { Digitalis }+ \\
\text { disopyramide }\end{array}$ \\
\hline Connolly et al. [21] & Double-blinded & 14 & $\mathrm{CABG}, \mathrm{ASD}, \mathrm{AVS}$ & Propafenone & $>$ & Placebo \\
\hline Gavaghan et al. [64] & Open & 56 & Not specified & Flecainide & $=$ & $\begin{array}{l}\text { Digitalis + } \\
\text { disopyramide }\end{array}$ \\
\hline Wafa et al. [63] & Open & 29 & CABG & Flecainide & $>$ & Digitalis \\
\hline McAlister et al. [42] & Open, crossover & 80 & CABG, AVS, MVS & Quinidine & $>$ & Amiodarone \\
\hline Hjelms et al. [61] & Open & 30 & CABG, VSD, AVS & Procainamide & $>$ & Digitalis \\
\hline Ollitrault et al. [65] & Double-blinded & 86 & CABG, AVS, MVS, CC & Cibenzoline & $>$ & Placebo \\
\hline Cochrane et al. [10] & Open & 30 & CABG. AVS, MVS & Amiodarone & $=$ & Digitalis \\
\hline Larbuisson et al. [62] & Open & 40 & CABG, AVS & Propafenone & $=$ & Amiodarone \\
\hline Frost et al. [67] & Double-blinded & 98 & CABG & Dofetilide & $=$ & Placebo \\
\hline
\end{tabular}

a $>$ : Proceeding A significantly more efficient in converting postoperative atrial tachyarrhythmias to sinus rhythm as compared to drug $\mathrm{B} ;=$ : no significant difference $(A S D$ atrial septal defect, $A V S$

Diltiazem [15] and verapamil [24, 27, 55] have been compared to placebo in open and double-blinded studies. No prophylactic effect for postoperative atrial tachyarrhythmia of either drug could be demonstrated. Patients given diltiazem experienced exactly the same incidence of supraventricular tachyarrhythmias as those in the placebo group. In addition, the diltiazem group needed significantly more inotropic support. In only one [55] of the three trials comparing verapamil to placebo was ventricular heart rate significantly lowered during atrial tachyarrhythmia. Moreover, a significant incidence of severe side effects, including hypotension and pulmonary edema, was observed [55].

Magnesium has been investigated in several trials. In a controlled study, a significantly higher incidence of atrial tachyarrhythmia was observed in hypomagnesemic compared to normomagnesemic patients [9]. However, prophylactic magnesium supplementation was ineffective. In accordance with this finding, hypomagnesemic patients experienced significantly more episodes of atrial fibrillation, but prophylactic magnesium did not significantly lower the number of patients experiencing atrial fibrillation [8]. Indeed, a nonsignificant increase in atrial fibrillation has been reported with prophylactic magnesium [56]. However, patients in this group were significantly older and more frequently had a history of atrial fibrillation compared with those receiving placebo.

The prophylactic use of postoperative digitalis is controversial. Some studies identified a positive effect [23, aortic valve surgery, $M V S$ mitral valve surgery, $V S D$ ventricular septal defect, $C A B G$ coronary artery bypass graft, $C C$ correction of congenital heart disease)

57]. By contrast, others [48] found a significant increase in postoperative atrial tachyarrhythmias with prophylactic digitalization. In a meta-analysis, only a trend toward a benefit was demonstrated [53].

Triiodothyronine, given for $9 \mathrm{~h}$ following unclamping of the aorta, was compared to placebo in a double-blinded manner in 131 patients with an ejection fraction of $<40 \%$ following coronary artery bypass grafting [18], and this led to a significant decrease in atrial fibrillation after $25-120 \mathrm{~h}$. However, possible mechanisms of action remain speculative.

\section{Therapy of postoperative atrial tachyarrhythmias}

The therapeutic goals of correcting atrial tachyarrhythmia are rapid reduction of the ventricular rate and early conversion to sinus rhythm [10]. In cases of hemodynamic instability, acute myocardial ischemia, or hypertrophic cardiomyopathy, for example, associated with severe aortic stenosis, DC cardioversion is the therapy of choice [58].

Even patients with chronic preoperative atrial fibrillation can be converted to sinus rhythm $[59,60]$, a successful conversion occuring in $60-77 \%$ of patients treated pharmacologically, with or without DC cardioversion. In all of these patients, atrial fibrillation was present for 48 to 72 months. A left atrial diameter less than $45-52 \mathrm{~mm}$, good functional capacity and shorter duration of preoperative atrial fibrillation were predic- 
tors of successful cardioversion; $70 \%$ remained in sinus rhythm over a mean follow-up period of 17 months [60]. Table 2 summarizes the results of randomized and prospective trials evaluating drug efficiency in converting postoperative atrial tachyarrhythmia to sinus rhythm.

\section{Drugs and efficiency}

\section{Procainamide}

In a small trial of 30 patients, procainamide $(25 \mathrm{mg} / \mathrm{min}$ up to $15 \mathrm{mg} / \mathrm{kg}$ intravenously) was compared to digitalis (0.75-1.0 mg i.v.) [61]. In the procainamide group significantly more patients ( 87 vs $60 \%$ ) converted to sinus rhythm and conversion occurred significantly faster (40 vs $540 \mathrm{~min}$ ). No serious complication was observed in the procainamide group.

\section{Propafenone}

Propafenone ( $2 \mathrm{mg} / \mathrm{kg}$ i. v. over $10 \mathrm{~min}$ ) was compared to placebo in a small double-blinded crossover study: $43 \%$ of patients converted within $10 \mathrm{~min}$ of receiving propafenone, but none after placebo [21]. In addition, the ventricular rate decreased significantly in the propafenone group, the only side effect being a decrease in systolic blood pressure of $9 \mathrm{mmHg}$. Propafenone $(1-2 \mathrm{mg} / \mathrm{kg}$ over $10 \mathrm{~min}$ followed by an infusion of $420 \mathrm{mg}$ in $24 \mathrm{~h}$ ) was compared to amiodarone $(2.5-5 \mathrm{mg} / \mathrm{kg}$ over $10 \mathrm{~min}$ followed by an infusion of $900 \mathrm{mg}$ in $24 \mathrm{~h}$ ) in 40 patients following coronary artery bypass grafting or aortic valve replacement [62]. No beta blocking agents, calcium channel blockers, or other antiarrhythmics were given concurrently. There was no significant difference between the two groups in terms of conversion rates or hemodynamic performance. Propafenone seemed to act slightly faster than amiodarone.

\section{Flecainide}

By comparison with digitalis $(0.5 \mathrm{mg}$ i.v. followed by $0.25 \mathrm{mg}$ after 6 and $12 \mathrm{~h}$ ) [63] flecainide $(1 \mathrm{mg} / \mathrm{kg}$ over $10 \mathrm{~min}$ followed by an infusion of $1.5 \mathrm{mg} / \mathrm{kg}$ per $\mathrm{h}$ for $1 \mathrm{~h}$, then $0.25 \mathrm{mg} / \mathrm{kg}$ per $\mathrm{h}$ for $24 \mathrm{~h}$ ) led to conversion to sinus rhythm significantly more often. No patient in the digitalis group converted to sinus rhythm. No serious side effects were observed in either group. Flecainide $(2 \mathrm{mg} / \mathrm{kg}$ i. v. over $20 \mathrm{~min}$ followed by an infusion of $0.2 \mathrm{mg} / \mathrm{kg}$ per $\mathrm{h}$ for $12 \mathrm{~h}$ ) compared to a combination of digitalis $(0.75 \mathrm{mg} \mathrm{i}$. v.) followed by disopyramide $2 \mathrm{~h}$ later $(2 \mathrm{mg} / \mathrm{kg}$ and an infusion of $0.4 \mathrm{mg} / \mathrm{kg}$ per h for $10 \mathrm{~h})$ showed almost identical conversion rates, but flecainide acted significantly faster ( 80 vs $220 \mathrm{~min}$ ) [64]. Considering the prolonged time for conversion using digitalis, this group of patients may have experienced spontaneous conversion. One fatality in the flecainide group was due to intractable ventricular fibrillation.

\section{Cibenzoline}

Cibenzoline $(1.2 \mathrm{mg} / \mathrm{kg}$ over $2 \mathrm{~min}$ i.v.) has been compared to placebo in a double-blinded trial, in which no other antiarrhythmics were given concurrently [65]. Significantly more patients of the active group converted to sinus rhythm ( 30 vs $6.9 \%$ ), and the ventricular rate was significantly lower. No side effects were noted in this study population, which had an average ejection fraction of approximately $60 \%$.

\section{Beta blockers}

No prospective randomized studies comparing the therapeutic use of beta blockers with other drugs or placebo have been performed.

\section{Amiodarone}

Amiodarone $(5 \mathrm{mg} / \mathrm{kg}$ up to $400 \mathrm{mg}$ over $30 \mathrm{~min}$, then $25 \mathrm{mg} / \mathrm{h}$ and a possible rise to $40 \mathrm{mg} / \mathrm{h}$ ) has been compared to digitalis $(1 \mathrm{mg}$ over $9 \mathrm{~h}$ i.v. followed by oral maintenance) [10] and showed comparable conversion rates to sinus rhythm within $24 \mathrm{~h}$. The ventricular rate during atrial fibrillation, blood pressure, and side effects were also comparable. Amiodarone $(5 \mathrm{mg} / \mathrm{kg}$ over $20 \mathrm{~min}$ i.v. $)$ was compared to Quinidine $(2 \times 400 \mathrm{mg}$ per os in $4 \mathrm{~h}$ ) in a randomized crossover study [42]. Significantly more patients converted under quinidine as with the first drug ( 64 vs $41 \%$ ), the difference being no more significant after the second. Side effects were observed in significantly more patients receiving quinidine first, some of which were severe (e.g., torsades de pointes, severe nausea and vomiting).

\section{Sotalol}

Sotalol ( $1 \mathrm{mg} / \mathrm{kg}$ bolus, plus $0.2 \mathrm{mg} / \mathrm{kg}$ over $12 \mathrm{~h})$ has been compared to a combination of digitalis plus disopyramide (digitalis $0.75 \mathrm{mg}$ i. v. followed $2 \mathrm{~h}$ later by disopyramide $2 \mathrm{mg} / \mathrm{kg}$ bolus and $0.4 \mathrm{mg} / \mathrm{kg}$ per h for $10 \mathrm{~h}$ ) [66]. Conversion rates were equal in both groups, but those in the sotalol group converted significantly faster (58 vs $187 \mathrm{~min}$ ) and had fewer relapses. The most frequent side effect attributable to sotalol was hypotension, leading to a drop in blood pressure of at least 
$20 \mathrm{mmHg}$, or to below $90 \mathrm{mmHg}$ in over $75 \%$ of patients. Disopyramide had to be stopped in several cases due to anticholinergic side effects.

\section{Dofetilide}

Dofetilide, a class III antiarrhythmic agent without negative inotropic effects, has been compared in a doubleblinded manner in two dosages $(4 \mu \mathrm{g} / \mathrm{kg}$ and $8 \mu \mathrm{g} / \mathrm{kg}$ over $15 \mathrm{~min}$ ) to placebo [67]. Within $3 \mathrm{~h}$ of drug administration, conversion rates were 24 and $44 \%$ for placebo and $8 \mu \mathrm{g} / \mathrm{kg}$ dofetilide respectively, a nonsignificant difference. Dofetilide was well tolerated and had no negative inotropic effect.

\section{Verapamil}

Verapamil $(0.075 \mathrm{mg} / \mathrm{kg}$ followed by $0.15 \mathrm{mg} / \mathrm{kg}$ later $)$ has been compared to placebo in two double-blinded crossover studies $[58,68]$. The ventricular heart rate during atrial fibrillation was significantly reduced, although the effect wore off rapidly after discontinuing the drug. Verapamil was not superior to placebo in conversion into sinus rhythm, but led to a significant reduction in diastolic blood pressure [58].

\section{Digitalis}

Digitalis has long been considered the drug of choice for supraventricular arrhythmia [10], although it has no intrinsic antiarrhythmic effect [69]. No prospective randomized studies have been done comparing digitalis to placebo. Digitalis alone or in combination with disopyramide was compared to procainamide, flecainide, cibenzoline, amiodarone, and sotalol, as summarized in Table 2, but in no case was digitalis better than the comparative drug. In addition, in the nonoperative setting digitalis does not convert atrial fibrillation faster or better than placebo [70]. It may have an indirect beneficial effect mediated via improvement of hemodynamic status [69] and lowering of heart rate.

\section{Anticoagulation}

Left atrial thrombus began to form in $14 \%$ of 143 patients with acute atrial fibrillation within 3 days, as detected by transesophageal echocardiography (TEE) [71]. However, among patients presenting with atrial fibrillation that was clinically estimated to have lasted less than $48 \mathrm{~h}$, the likelihood of cardioversion - related clinical thromboembolism was very low [72]. The use of TEE to identify atrial thrombus and decide on its sever- ity is controversial [73, 74]. A meta-analysis of three randomized trials has suggested a small positive effect of aspirin in preventing stroke [75]. Anticoagulation with warfarin is more effective and significantly reduces the incidence of embolism [76-78]. But all studies mentioned have been performed in a nonpostoperative setting. Therefore, no therapeutic guidelines exist for patients after cardiac surgery. The risk of thromboembolism must be weighed against the possible hazard of anticoagulation, especially when administered shortly after major surgery. A reasonable approach at present is that if atrial fibrillation persists for $24 \mathrm{~h}$ or more, anticoagulation should be started.

\section{A practical approach}

As in the management of any other medical problem, all patients have to be evaluated on an individual basis, considering factors such as type of operation, age, preoperative medication, and hemodynamic status.

\section{Prophylaxis}

Older patients, with a history of atrial fibrillation undergoing heart valve operations are at an increased risk and benefit from pharmacological prophylaxis. As the peak incidence of atrial tachyarrhythmia is during the second to third postoperative day, prophylaxis should be started as early as possible. Beta blockers are the most widely investigated drugs for the prophylaxis of postoperative atrial tachyarrhythmias and are considered by many to be the drug of choice. In established preoperative beta blockade, they should be continued during the whole postoperative period. Combined therapy with digitalis may be considered in patients with depressed left ventricular function. Sotalol has been used with good results and may even be superior to other beta blockers. In the case of intolerance to beta blockers, amiodarone and propafenone has been shown to be effective. Presently none of the data justify the prophylactic use of digitalis alone, nor calcium antagonists. In recurrent atrial tachyarrhythmia, amiodarone or sotalol may be used as prophylaxis, even if controlled studies are lacking. No data exist concerning the duration of prophylactic medication.

\section{Therapy}

In patients with hemodynamically poorly tolerated atrial tachyarrhythmia, DC cardioversion is imperative. In the case of hemodynamic stability, the goal of therapy is to control ventricular rate and convert to sinus rhythm. If ventricular function is normal, rate control may be achieved using careful titration of beta blockers. 
Digitalis may be considered in patients with congestive heart failure.

If conversion to sinus rhythm does not occur spontaneously, procainamide, propafenone, or flecainide is effective and safe for pharmacologic cardioversion. No controlled studies indicate that the use of beta blockers or calcium antagonists is justified in cardioversion. Although used by many, no convincing data exist either for the use of amiodarone or digitalis. We do not recommend prolonged use of flecainide due to its possible proarrhythmic effect. If atrial fibrillation is recurrent or lasts more than $24 \mathrm{~h}$, intravenous anticoagulation with heparin, followed by oral anticoagulation, is recommended. Two to four weeks of anticoagulation is prudent before elective DC cardioversion.

\section{References}

1. Matangi MF, Neutze JM, Graham KJ, Hill DG, Kerr AR, Barratt-Boyes BG (1985) Arrhythmia prophylaxis after aorta-coronary bypass. I Thorac Cardiovasc Surg 89: 439-443

2. Janssen J, Loomans L, Harink J, Taams M, Brunninkhuis L, van der Starre P, Kootstra G (1986) Prevention and treatment of supraventricular tachycardia shortly after coronary artery bypass grafting: a randomized open trial. Angiology 37: 601-609

3. Rubin DA, Nieminski KE, Reed GE, Herman MV (1987) Predictors, prevention, and long-term prognosis of atrial fibrillation after coronary artery bypass graft operations. J Thorac Cardiovasc Surg 94: 331-335

4. Khuri SF, Okike ON, Josa M, Salm TJV, Saaoussa S, Leone L, Silverman A, Siouffi S, Olukotun AY (1987) Efficacy of nadolol in preventing supraventricular tachycardia after coronary artery bypass grafting. Am J Cardiol 60: $51 \mathrm{D}-58 \mathrm{D}$

5. Lamb RK, Prabhakar G, Thorpe JAC, Smith S, Norton R, Dyde JA (1988) The use of atenolol in the prevention of supraventricular arrbythmias following coronary artery surgery. Eur Heart J 9: 32-36

6. Fuller JA, Adams GG, Buxton B (1989) Atrial fibrillation after coronary artery bypass grafting. J Thorac Cardiovasc Surg 97: 821-825

7. Taylor GJ, Mikell FL, Moses W, Dove JT, Katholi RE, Malik SA, Markwell SJ, Korsmeyer C, Schneider JA, Wellons HA (1990) Determinants of hospital charges for coronary artery bypass surgery: the economic consequences of postoperative complications. Am J Cardiol 65: 309-313

8. Fanning WJ, Thomas CS, Roach A, Tomichek R, Alford WC, Stoney WS (1991) Prophylaxis of atrial fibrillation with magnesium sulfate after coronary artery bypass grafting. Ann Thorac Surg 52: 529-533
9. England MR, Gordon G, Salem M, Chernow B (1992) Magnesium administration and dysrhythmias after cardiac surgery. JAMA 268: 2395-2402

10. Cochrane AD, Siddins M, Rosenfeldt FL, Salamonsen R, McConaghy L, Marasco S, Davis BB (1994) A comparison of amiodarone and digoxin for treatment of supraventricular arrhythmias after cardiac surgery. Eur J Cardiothorac Surg 8: 194-198

11. Steinberg JS, Zelenkofske S, Wong SC, Gelernt M, Sciacca R, Menchavez E (1993) Value of the p-ware signal averaged ECG for predicting atrial fibrillation after cardiac surgery. Circulation 88: 2618-2622

12. Mendes LA, Connelly GP, McKenny PA, Podrid PJ, Cupples A, Shemin RJ Ryan TJ, Davidoff R (1995) Right coronary artery stenosis: an independent predictor of atrial fibrillation after coronary artery bypass surgery. J Am Coll Cardiol 25: 198-202

13. Frost L, Molgaard H, Christiansen EH, Jacobsen C-J. Pilegaard H. Thomsen PEB (1995) Atrial ectopic activity and atrial fibrillation/flutter after coronary artery bypass surgery. A case-pase study controlling for confounding from age, beta blocker treatment, and time distance from operation. Int J Cardiol 50 : 153-162

14. Merrick AF, Odom NJ, Keenan DJM, Grotte GJ (1995) Comparison of propafenone to atenolol for the prophylaxis of postcardiotomy supraventricular tachyarrhythmias: a prospective trial. Eur J Cardiothorac Surg 9: 146-149

15. Babin-Ebell J, Keith PR, Elert O (1996) Efficacy and safety of low dose propranolol versus diltiazem in the prophylaxis of supraventricular tachyarrhythmia after coronary artery bypass grafting. Eur J Cardiothorac Surg 10: 412-416

16. Mathew JP, Parks R, Savino JS, Friedman AS, Koch C, Mangano DT, Browner WS (1996) Atrial fibrillation following coronary artery bypass graft surgery. JAMA 276: 300-306
17. Aranki AF, Shaw DP, Adams DH, Rizzo RJ, Couper GS, Vanderviet M, Collins JJ, Cohn LH, Burstin HR (1996) Predictors of atrial fibrillation after coronary artery surgery. Circulation 94: 390-397

18. Klemperer JD, Klein IL, Ojamaa K, Helm RE, Gomez M, Isom OW, Krieger KH (1996) Triiodothyronine therapy lowers the incidence of atrial fibrillation after cardiac operations. Ann Thorac Surg 61: 1323-1329

19. Kowey PR, Dalessandro DA, Herbertson R, Briggs B, Wertan MAC, Rials SJ, Filart RA, Marichak RA (1997) Effectiveness of digitalis with or without acebutolol in preventing atrial arrhythmias after coronary artery surgery. Am J Cardiol 79: 1114-1117

20. Creswell LL, Schuessler RB, Rosenbloom M, Cox JL (1993) Hazards of postoperative atrial arrhythmias. Ann Thorac Surg 56: 539-549

21. Connolly SJ, Mulji AS, Hoffert DL, Davis CD, Shragge BW (1987) Randomized placebo controlled trial of propafenon for treatment of atrial tachyarrhythmias after cardiac surgery. J Am Coll Cardiol 10: 1145-1148

22. Daudon P, Corcos T, Gandjbakhch I, Levasseur J-P, Cabrol A, Cabrol C (1986) Prevention of atrial fibrillation or flutter by acebutolol after coronary bypass grafting. Am J Cardiol 58: 933-936

23. Johnson LW, Dickstein RA, Fruehan CT. Kane P, Potts JL, Smulyan H, Webb WR, Eich RH (1976) Prophylactic digitalization for coronary artery bypass surgery. Circulation 53: 819-822

24. Smith EEJ, Shore DF, Monro JL, Ross JK (1985) Oral verapamil fails to prevent supraventricular tachycardia following coronary artery surgery. Int $J$ Cardiol 9: 37-44

25. Kalman JM, Munawar M, Howes LG, Louis WJ. Buxton BF, Gutteridge G, Tonkin AM (1995) Atrial fibrillation after coronary artery bypass grafting is associated with sympathetic activation. Ann Thorac Surg 60: 1709-1715 
26. Nyström U, Edvardsson N, Berggren $H$, Pizzarelli G-P, Radegran K (1993) Sotalol reduces the incidence of atrial fibrillation after coronary artery bypass surgery. Thorac Cardiovasc Surg 41: 34-37

27. Williams DB, Misbach GA, Kruse AP, Ivey TD (1985) Oral verapamil for prophylaxis of supraventricular tachycardia after myocardial revascularization. J Thorac Cardiovasc Surg 90: 592-596

28. Moller Jensen B, Alstrup P, Klitgard NA (1996) Postoperative arrhythmias and myocardial electrolytes in patients undergoing coronary artery bypass grafting. Scand J Thorac Cardiovasc Surg 30: 133-140

29. Moe GK, Abildskov JA (1959) Atrial fibrillation as a self-sustaining arrhythmia independent of focal discharge. Am Heart J 58: 59-70

30. Allessie MA, Bonke FIM, Schopman FJG (1977) Circus movement in rabbit atrial muscle as a mechanism of tachycardia. Circ Res 41: 9-18

31. Kirchhof C, Chorro F, Scheffer GJ, Brugada J, Konings K, Zetelaki Z, Allessie M (1993) Regional entrainment of atrial fibrillation studied by high-resolution mapping in open chest dogs. Circulation 88: 736-749

32. Jasi P, Haissaguerre M, Shah DC, Chouairi S, Gencel L, Hocini M, Clömenty J (1997) A focal source of atrial fibrillation treated by discrete radiofrequency ablation. Circulation 95: 572-576

33. De Leeuw PW, van der Starre PJA, Harinck-de Weerdt JE, de Bos R, Tchang PT, Birkenhäger WH (1983) Humoral changes during and following coronary bypass surgery: relationship to postoperative blood pressure. J Hypertens 1 [Suppl 2]: 52-54

34. Davies MJ, Pomerance A (1972) Pathology of atrial fibrillation in man. $\mathrm{Br}$ Heart J 34: 520-525

35. Manyari DE, Patterson C, Johnson D, Melendez L, Kostuk WJ, Cape RDT (1990) Atrial and ventricular arrhythmias in asymptomatic active elderly subjects: correlation with left atrial size and left ventricular mass. Am Heart J 119: 1069-1076

36. Lie JT, Hammond PI (1988) Pathology of the senescent heart: anatomic observations of 237 autopsy studies of patients 90 to 105 years old. Mayo Clin Proc 63: 552-564

37. Aranow WS, Schwartz KS, Koenigsberg M (1987) Correlation of atrial fibrillation with presence or absence of mitral annular calcium in 604 persons older than 60 years. Am J Cardiol 59: 1213-1214
38. Hirsch IA, Tomlinson DL, Slogoff S, Keats AS (1988) The overstated risk of preoperative hypokalemia. Anesth Analg 67: 131-136

39. Casthely PA, Yoganathan T, Korner C, Kelly M (1994) Magnesium and arrhythmias after coronary artery bypass surgery. J Cardiothorac Vasc Anesth 8: 188-191

40. Frost L, Jacobsen C-J, Chrisiansen EH, Molgaard H, Pilegaard H, Hjortholm K, Thomsen PEB (1995) Hemodynamic predictors of atrial fibrillation or flutter after coronary artery bypass grafting. Acta Anaesthesiol Scand 39: 690-697

41. Hashimoto K, Ilstrup DM, Schaff HV (1991) Influence of clinical and hemodynamic variables on risk of supraventricular tachycardia after coronary artery bypass. J Thorac Cardiovasc Surg 101: 56-65

42. McAlister HF, Luke RA, Whitlock RM, Smith WM (1990) Intravenous amiodarone bolus versus oral quinidine for atrial flutter and fibrillation after cardiac operations. J Thorac Cardiovasc Surg 99: 911-918

43. Klein M, Evans SJL, Blumberg S, Caaldo L, Bodenheimer MM (1995) Use of P-wave-triggered, P-wave signal-averaged electrocardiogram to predict atrial fibrillation after coronary artery bypass surgery. Am Heart J 129: 895-901

44. Suttorp MJ, Kingma JH, Peels HOJ, Koomen EM, Tijssen JGP, van Hemmel NM. Defauw JAM, Ernst SMPG (1991) Effectiveness of sotalol in preventing supraventricular tachyarrhythmias shortly after coronary artery bypass grafting. Am J Cardiol 68: 1163-1169

45. Caretta Q, Mercanti CA, De Nardo D, Chiarotti F, Scibilia G, Reales A, Marino B (1991) Ventricular conduction defects and atrial fibrillation after coronary artery bypass grafting. Multivariate analysis of preoperative, intraoperative and postoperative variables. Eur Heart J 12: 1107-1111

46. Genitli C, Giordano F, Alois A, Massa E, Bianconi L (1992) Efficacy of intravenous propafenone in acute atrial fibrillation complicating open heart surgery. Am Heart J 123: 1225-1228

47. Reed GL III, Singer DE, Picard EH, DeSanctis RW (1988) Stroke following coronary artery bypass surgery. N Engl J Med 319: 1246-1250

48. Tyras DH. Stothert JC, Kaiser GC, Barner HB, Codd JE, Willman VL (1979) Supraventricular tachyarrhythmias after myocardial revascularization: a randomized trial of prophylactic digitalization. J Thorac Cardiovase Surg 77 : 310-314
49. Taylor GJ, Malik SA, Colliver JA, Moses HW, Mikell FL, Batchelder JE, Schneider JA, Wellons HA (1987) Usefulness of atrial fibrillation as a predictor of stroke after isolated coronary artery bypass grafting. Am J Cardiol 60: 905-907

50. Lowe JE, Hendry PJ, Hendrickson SC, Wells R (1991) Intraoperative identification of cardiac patients at risk of develop postoperative atrial fibrillation. Ann Surg 213: 388-392

51. Kolvekar S, D'Souza A, Akhatar P, Reek C, Garratt C, Spyt T (1997) Role of atrial ischaemia in development of atrial fibrillation following coronary artery bypass surgery. Eur J Cardiothorac Surg 11: 70-75

52. Hammon JW, Wood AJJ, Prager RL, Wood MW, Muirhead J, Bender HW (1984) Perioperative betablockade with propranolol: reduction in myocardial oxygen demands and incidence of atrial and ventricular arrhythmias. Ann Thorac Surg 38: 363-367

53. Kowey PR, Taylor JE, Rials SJ, Marinchak RA (1992) Meta analysis of the effectiveness of prophylactic drug therapy in preventing supraventricular arrhythmia early after coronary artery bypass grafting. Am J Cardiol 69: 963-965

54. Hohnloser SH, Meinertz T, Dammbacher T, Steiert K, Jähnchen E, Zehender M, Fraedrich G, Just H (1991) Electrocardiographic and antiarrhythmic effects of intravenous amiodarone: results of a prospective, placebo controlled study. Am Heart J 121: 89-95

55. Davison R, Hartz R, Kaplan K, Parker M, Feiereisel P, Michaelis L (1985) Prophylaxis of supraventricular tachyarrhythmia after coronary bypass surgery with oral verapamil: a randomized, double blind trial. Ann Thorac Surg 39: 336-339

56. Parikka H, Toivonen L, Pellinen T, Verkkalla K, Järvinen A, Nieminen MS (1993) The influence of intravenous magnesium sulphate on the occurrence of atrial fibrillation after coronary artery bypass operation. Eur Heart J 14: 251-258

57. Csicsko JF, Schatzlein MH, King RD (1981) Immediate postoperative digitalization in the prophylaxis of supraventricular arrhythmias following coronary artery bypass. J Thorac Cardiovasc Surg 81: 419-422

58. Hwang MH, Danoviz J, Pacold I, Rad N, Loeb HS, Gunnar RM (1984) Double blind crossover randomized trial of intravenously administered verapamil. Arch Intern Med 144: 491-494 
59. Flugelman MY, Hasin Y, Katznelson N, Kriwisky M, Shefer A, Gotsman MS (1984) Restoration and maintenance of sinus rhythm after mitral valve surgery for mitral stenosis. Am J Cardiol 54 $617-619$

60. Skoularigis J, Röthlisberger C, Skudicky D, Essop MR, Wisenbaugh T, Sareli $P$ (1993) Effectiveness of amiodarone and electrical cardioversion for chronic rheumatic atrial fibrillation after mitral valve surgery. Am J Cardiol 72: 423-427

61. Hjelms E (1992) Procainamide conversion of acute atrial fibrillation after open heart surgery compared with digoxin treatment. Scand J Thorac Cardiovase Surg 26: 193-196

62. Larbuisson R, Venneman I, Stiels B (1996) The efficacy and safety of intravenous propafenon versus intravenous amiodarone in the conversion of atrial fibrillation or flutter after cardiac surgery. J Cardiothorac Vasc Anesth 10: 229-234

63. Wafa SS, Ward DE, Parker DJ, Camm AJ (1989) Efficacy of flecainide acetate for atrial arrhythmias following coronary artery bypass grafting. Am J Cardiol 63: 1058-1064

64. Gavaghan TP, Keogh AM, Kelly RP, Campbell TJ, Thorburn C, Morgan JJ (1988) Flecainide compared with a combination of digoxin and disopyramide for acute atrial arrhythmias after cardiopulmonary bypass. Br Heart J 60: 497-501

65. Ollitrault J, Quilliet L, Scheck F, Lelong B, Richard A, Jarry G, Guize L (1994) Single infusion of intravenous cibenzoline in the treatment of supraventricular tachyarrhythmias following heart surgery. Eur Heart J 15: 1274-1278

66. Campbell TJ, Gavaghan TP, Morgan JJ (1985) Intravenous sotalol for the treatment of atrial fibrillation and flutter after cardiopulmonary bypass. Br Heart J 54: 86-90

\section{Note added in proof}

In the meantime, a prospective double blind study has found an advantageous effect of prophylactic amiodarone over placebo. Daoud EG (1997) Preoperative amiodarone as prophylaxis against atrial fibrillation after heart surgery. $\mathrm{N}$ Engl J Med 337: 1785-1791
67. Frost L, Mortensen PE, Tingleff J, Platou ES, Christiansen EH, Christiansen $\mathrm{N}$ (1997) Efficacy and safety of dofetilide, a new class III antiarrhythmic agent, in acute termination of atrial fibrillation or flutter after coronary artery bypass surgery. Int $\mathrm{J}$ Cardiol 58 : $135-140$

68. Plumb VJ, Karp RB, Kouchoukos NT, Zorn GL, James TN, Waldo AL (1982) Verapamil therapy of atrial fibrillation and atrial flutter following cardiac operation. J Thorac Cardiovasc Surg 83: 590-596

69. Krohn BG, Saenz JM, Eto KK (1989) Critical dose of digoxin for treating supraventricular tachycardias after heart surgery. Chest 95: 729-734

70. Falk RH, Knowlton AA, Bernard SA, Gotlieb NE, Battinelli NJ (1987) Digoxin for converting recent onset atrial fibrillation to sinus rhythm. Ann Intern Med 106: 503-506

71. Stoddard MF, Dawkins PR, Prince CR, Ammash NM (1995) Left atrial appendage thrombus is not uncommon in patients with acute atrial fibrillation and a recent embolic event: a transesophageal echocardiographic study. J Am Coll Cardiol 25: 452-459

72. Weigner MJ, Caulfield TA, Danias PG, Silverman DI, Manning WJ (1997) Risk for clinical thromboembolism associated with conversion to sinus rhythm in patients with atrial fibrillation lasting less than 48 hours. Ann Intern Med 126: 615-620

73. Manning WJ, Silverman DI, Gordon SP, Krumholz HM, Douglas PS (1993) Cardioversion from atrial fibrillation without prolonged anticoagulation with use of transesophageal echocardiography to exclude the presence of atrial thrombi. N Engl J Med 328: 750-755
74. Black IW, Fatkin D, Sagar KB, Khandheria BK, Leung DY, Galloway JM, Feneley MP, Walsh WF, Grimm RA, Stollberger C, Verhorst PMJ, Klein AL (1994) Exclusion of atrial thrombus by transesophageal echocardiography does not preclude embolism after cardioversion of atrial fibrillation. Circulation; 89: 2509-2513

75. The Atrial Fibrillation Investigators (1997) The efficacy of aspirin in patients with atrial fibrillation. Arch Intern Med 157: 1237-1240

76. The Atrial Fibrillation Investigators (1994) Risk factors for stroke and efficacy of antithrombotic therapy in atrial fibrillation. Arch Intern Med 154: 1449-1457

77. Stroke prevention in Atrial Fibrillation Investigators (1991) Stroke prevention in atrial fibrillation study. Circulation 84: $527-539$

78. Petersen P, Boysen G, Godtfredsen J, Andersen ED, Andersen B (1989) Placebo-controlled, randomised atrial of warfarin and aspirin for prevention of thromboembolic complications in chronic atrial fibrillation. Lancet $\mathrm{I}$ : 175-179

Appendix. A professional search was performed by the documentation service of the Swiss Academy of Medical Sciences using Medline databank. The English language literature from 1982 until May 1997 was considered. The mesh headings "atrial fibrillation, atrial flutter" and "tachycardia, supraventricular" were combined with the mesh headings "heart" and "surgery" using subheadings "coronary artery bypass, heart bypass, heart valve, internal mammary artery anastomosis, arrhythmias, etiology" and others, respectively. Furthermore, the Current Contents databank was searched using the same keywords. Additional material was found using the reference lists of all the above retrieved articles. 